\title{
Quantitative Economics Editor's Annual Report for year ending June 30, 2019 Christopher Taber
}

\section{IntRoduction to TABLES AND CHARTS, Highlights, AND ADDITIONAL} INFORMATION

This annual report presents tables, graphs, classification analysis, and additional information.

Table 1 presents the status of manuscripts. The number of submissions during the past year was 212, which is a modest reduction from last year's 250 submissions but higher than the previous years 173. Table 2 describes how the new submissions were distributed among co-editors. Table 3 provides data on the time to first decision for decisions made in this reporting year; $85 \%$ of decisions on new submissions and $97 \%$ of decisions on revisions were made within 6 months. The respective percentages last year were almost the same, $87 \%$ and $90 \%$.

The time between acceptance and publication has averaged 10.25 during this past year which is a decrease from last year's reported 11.5 months. We increased the number of issues starting in January 2019 from 3 to 4 and if we continue to publish more papers in the QE issues (as we have been) there should be a drop in time for QE next year.

Figures 1-2 provide a more visual description of the time to decisions. For all the papers whose decisions were made during the past year, the mean time to decision was 104 days, while for all decisions made during the last three years, that mean was 102 days. The corresponding numbers in last year's report were 97 and 102. The median number of days to first decision of all papers whose decision were made during the past year was 98, while the corresponding number in last year's report was 105 .

The number of submissions where the authors asked to transfer the correspondence for their papers from Econometrica to Quantitative Economics decreased from 26 last year to 19 this year.

On the Associate Editors front, Jaap Abbring (Tilburg University), Hanming Fang (University of Pennsylvania), Rosemarie Nagel (Universitat Pompeu Fabra), Michael Reiter (Institute for Advanced Studies), Juan F. Rubio-Ramírez (Emory University), Manuel Santos (University of Miami), Şevin Yeltekin (Carnegie Mellon University), Francesca Molinari (Cornell University), Daniel Xu (Duke University) have rotated off. We have nine new Associate Editors: Francesco Bianchi (Duke University), Rafael Dix-Carneiro (Duke University), Jeremy Fox (Rice University), Zheng Liu (Federal Reserve Bank of San Francisco), Douglas L. Miller (Cornell University), Nicholas W. Papageorge (Johns Hopkins University), Xiaoxia Shi (University of Wisconsin, Madison), Charles Sprenger (University of California, San Diego), and Jessica A. Wachter (University of Pennsylvania).

(c) 2019 The Author. Licensed under the Creative Commons Attribution-NonCommercial License 4.0. Available at http://qeconomics.org. https://doi.org/10.3982/QE_REPORT_2020 
TABLE 1. Status of manuscripts.

\begin{tabular}{lcrrrrr}
\hline & $13 / 14$ & $14 / 15$ & $15 / 16$ & $16 / 17$ & $17 / 18$ & $18 / 19$ \\
\hline In process at beginning of year & 43 & 39 & 57 & 63 & 62 & 85 \\
New papers received & 90 & 123 & 149 & 173 & 250 & 212 \\
Revisions received & 43 & 51 & 64 & 76 & 85 & 81 \\
Papers accepted & 27 & 19 & 30 & 32 & 40 & 43 \\
Papers conditionally accepted & 13 & 8 & 20 & 22 & 16 & 20 \\
Papers returned for revision & 34 & 53 & 65 & 56 & 70 & 65 \\
Papers rejected & 63 & 74 & 92 & 141 & 185 & 178 \\
[of these rejected without full refereeing]: & {$[21]$} & {$[25]$} & {$[37]$} & {$[50]$} & {$[66]$} & {$[62]$} \\
Papers Withdrawn & $* 0$ & 2 & 2 & 1 & 2 & 1 \\
Papers in process at end of year & 39 & 57 & 63 & 62 & 85 & 72 \\
\hline
\end{tabular}

TABLE 2. Distribution of new papers among co-editors.

\begin{tabular}{|c|c|c|c|c|c|c|}
\hline & & $14 / 15$ & $15 / 16$ & $16 / 17$ & $17 / 18$ & $18 / 19$ \\
\hline \multirow[t]{6}{*}{ Current Editors } & Taber & & & & 97 & 74 \\
\hline & Arcidiacono & & & 33 & 35 & 33 \\
\hline & Santos & & & & 38 & 35 \\
\hline & Storesletten & & & & 32 & 26 \\
\hline & Zha & & & & & 43 \\
\hline & Guest & & & 5 & 3 & 1 \\
\hline \multirow[t]{5}{*}{ Previous Editors } & Matzkin & 44 & 58 & 71 & & \\
\hline & Schmedders & 27 & 32 & 25 & & \\
\hline & Schorfheide & 29 & 35 & 39 & 45 & \\
\hline & Todd & 23 & 24 & & & \\
\hline & TOTAL: & 123 & 149 & 173 & 250 & 212 \\
\hline
\end{tabular}

Table 3. Time to decision.

\begin{tabular}{|c|c|c|c|c|c|c|c|c|c|}
\hline & \multicolumn{3}{|c|}{ Decisions on New Submissions } & \multicolumn{3}{|c|}{ Decisions on Revisions } & \multicolumn{3}{|c|}{ Decisions on All Papers } \\
\hline & $\#$ & $\%$ & Cumulative $\%$ & $\#$ & $\%$ & Cumulative \% & $\#$ & $\%$ & Cumulative \% \\
\hline In $\leq 1$ months: & & $30 \%$ & $30 \%$ & 36 & $41 \%$ & $41 \%$ & 101 & $33 \%$ & $33 \%$ \\
\hline In 2 months: & 7 & $3 \%$ & $33 \%$ & 16 & $18 \%$ & $60 \%$ & 23 & $8 \%$ & $41 \%$ \\
\hline In 3 months: & 34 & $16 \%$ & $48 \%$ & 12 & $14 \%$ & $74 \%$ & 46 & $15 \%$ & $56 \%$ \\
\hline In 4 months: & 25 & $11 \%$ & $60 \%$ & 7 & $8 \%$ & $82 \%$ & 32 & $10 \%$ & $66 \%$ \\
\hline In 5 months: & 37 & $17 \%$ & $77 \%$ & 9 & $10 \%$ & $92 \%$ & 46 & $15 \%$ & $81 \%$ \\
\hline In 6 months: & 18 & $8 \%$ & $85 \%$ & 4 & $5 \%$ & $97 \%$ & 22 & $7 \%$ & $88 \%$ \\
\hline In 7 months: & 10 & $5 \%$ & $89 \%$ & 1 & $1 \%$ & $98 \%$ & 11 & $4 \%$ & $92 \%$ \\
\hline In 8 months: & 7 & $3 \%$ & $93 \%$ & 1 & $1 \%$ & $99 \%$ & 8 & $3 \%$ & $94 \%$ \\
\hline In > 8 months: & 16 & $7 \%$ & $100 \%$ & 1 & $1 \%$ & $100 \%$ & 17 & $6 \%$ & $100 \%$ \\
\hline Total: & 219 & & & 87 & & & 306 & & \\
\hline
\end{tabular}

As in the previous years, QE benefitted enormously from the management of Mary Beth Bellando-Zaniboni. Her dedication and initiative, as well as her constant reliable support to the editors and authors have been critical for QE's operations. 


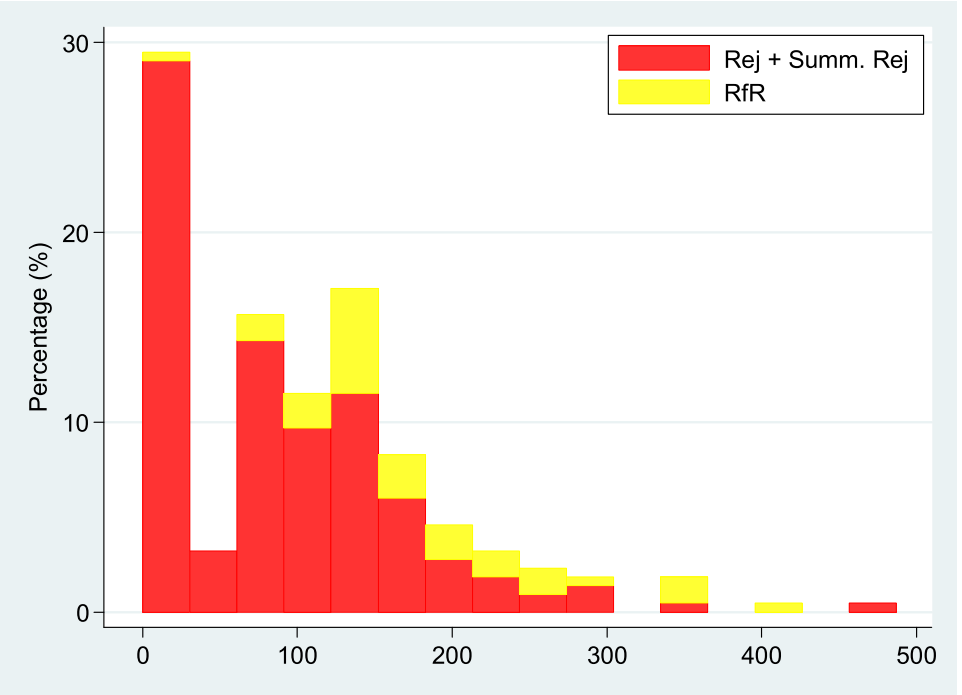

Figure 1. Statistics on Paper Handling

Average Days to First Decision: 104

Median Days to First Decision: 98

Decisions made in the last reported year

The above bar chart gives data on the time to first decision for decisions made during July 1 , 2018-June 30, 2019.

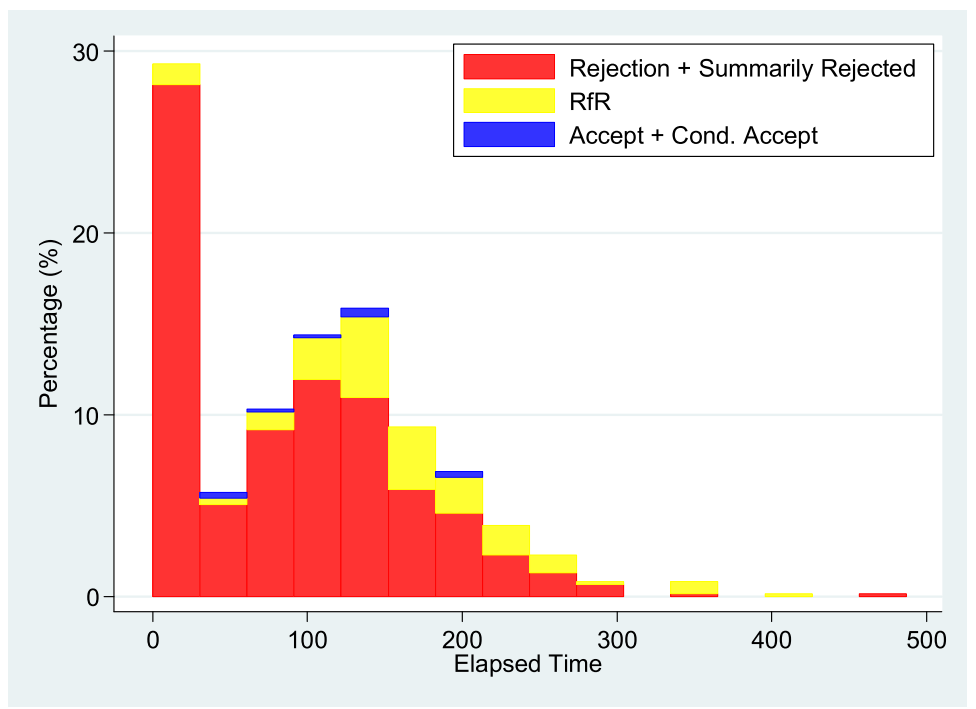

FIgURE 2. All decisions made during reported years 2016-2019

Average Days to First Decision: 102

Median Days to First Decision: 104

The above bar chart gives data on the time to first decision for decisions made during July 1 , 2016-June 30, 2019. 